Provided for non-commercial research and education use. Not for reproduction, distribution or commercial use.

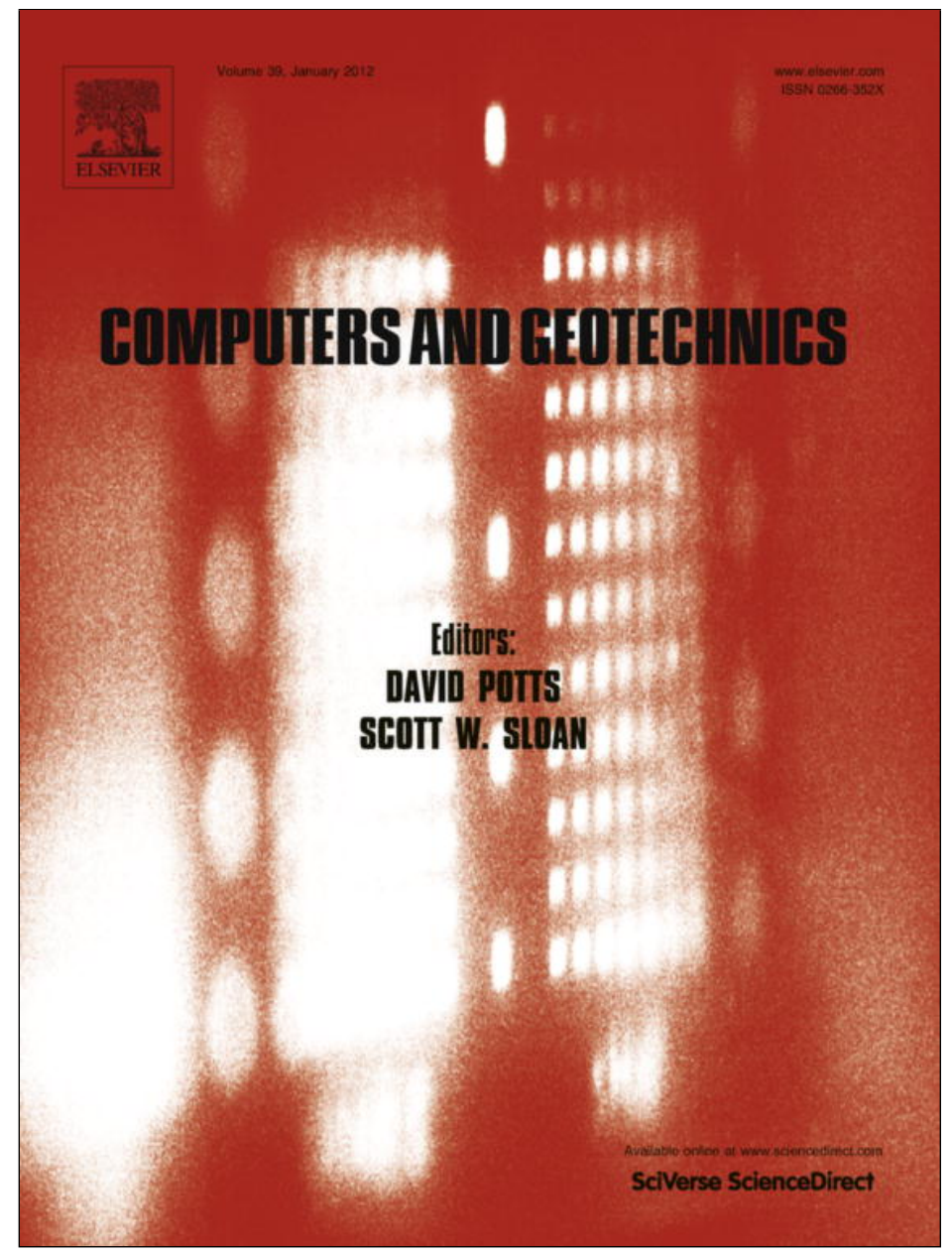

(This is a sample cover image for this issue. The actual cover is not yet available at this time.)

This article appeared in a journal published by Elsevier. The attached copy is furnished to the author for internal non-commercial research and education use, including for instruction at the authors institution and sharing with colleagues.

Other uses, including reproduction and distribution, or selling or licensing copies, or posting to personal, institutional or third party websites are prohibited.

In most cases authors are permitted to post their version of the article (e.g. in Word or Tex form) to their personal website or institutional repository. Authors requiring further information regarding Elsevier's archiving and manuscript policies are encouraged to visit:

http://www.elsevier.com/copyright 


\title{
3D stability analysis of gravity dams on sloped rock foundations using the limit equilibrium method
}

\author{
Eduardo M. Bretas ${ }^{\mathrm{a}}$, Pierre Léger ${ }^{\mathrm{b}, *}$, José V. Lemos ${ }^{\mathrm{c}}$ \\ a Universidade do Minho, Escola de Engenharia, Campus de Azurem, 4800-058 Guimaraes, Portugal \\ ${ }^{\mathrm{b}}$ Dept. of Civil, Geological, and Mining Engineering, École Polytechnique, P.O. Box 6079, Station CV, Montréal, Québec, Canada H3C $3 A 7$ \\ ${ }^{\mathrm{c}}$ Laboratório Nacional Engenharia Civil (LNEC), Lisbon, Portugal
}

\section{A R T I C L E I N F O}

\section{Article history:}

Received 12 October 2011

Received in revised form 23 March 2012

Accepted 22 April 2012

\section{Keywords:}

Concrete gravity dam

Three-dimensional analysis

Sliding

Limit equilibrium

Sloped rock foundation

Gravity method

\begin{abstract}
A B S T R A C T
A convenient approach to performing stability analysis of concrete gravity dams is the so-called twodimensional "gravity method." However, concrete gravity dams located in valleys with sloped rock foundation abutments behave as three-dimensional (3D) structures and are often able to share compressive and shear loads between adjacent monoliths, especially when shear keys are present. A general 3D limit equilibrium method was developed in this study to compute global sliding safety factors $\left(S_{S} F_{g}\right)$ by considering sequential load redistribution among adjacent monoliths when individual monoliths have mobilized their sliding strength. Two validation examples of the sliding safety assessment of existing dams are presented to illustrate the accuracy and efficiency of the proposed approach compared to that of the full 3D numerical analyses conducted using the distinct element method. It is shown that gravity dams may be formed by individual monoliths on sloped rock foundations that will slide if considered as isolated structures but will constitute a stable assembly when the load-sharing capabilities of monoliths are recognized in the analysis.
\end{abstract}

(c) 2012 Elsevier Ltd. All rights reserved.

\section{Introduction}

Two-dimensional structural models are currently widely used for the sliding stability analysis of straight gravity dams. The tallest section, usually located on the valley bottom, is typically selected for evaluation because it is usually the most critical part of the structure. The sliding failure mechanism considers motion only in the upstream-downstream direction [1,2].

In some cases, the conventional 2D analysis method, also known as the gravity method, is not the most adequate analysis method. Three dimensional behavior is most often the case of dams in narrow valleys, in which the height of the blocks can vary significantly, even between adjacent blocks that will experience different displacements. The blocks are subject to different hydrostatic pressures and have different stiffnesses. This is true, for example, when the blocks of the dam possess significant geometric variations that could induce torsional moments across the contraction joint due to the interaction between the concrete monoliths. A change of cross section may occur not only in dams constructed in sloping valleys, but they may also occur in dams constructed in planar valleys, such as in the transition from a non-overflow section to a discharge profile. If vertical joints are provided with

\footnotetext{
* Corresponding author. Tel.: +1 514340 4711x3712; fax: +1 5143405881.

E-mail addresses: eduardombretas@gmail.com (E.M. Bretas), pierre.leger@ polymtl.ca (P. Léger), vlemos@lnec.pt (J.V. Lemos).
}

shear keys, regardless of whether or not they are grouted, consecutive blocks will probably share some of the load.

Some reports of gravity dam failures demonstrate the appropriateness of considering the dam as a three-dimensional body [3]. An example is the failure of the Khadakwasla Dam, a masonry dam located in India, which has a maximum height of $33 \mathrm{~m}$. The rupture occurred in July 1961 following a flood caused by the rupture of an earth dam upstream of this dam. The rupture of the Khadakwasla Dam was partial and took place in a section that was only $2 / 3$ of the maximum height based on an area of the foundation that had a major discontinuity [4]. Another case, perhaps the best known, is the rupture of the St. Francis Dam, which has a height of $64 \mathrm{~m}$ and is located near Los Angeles, USA. The rupture occurred in March 1928 and killed 450 people. Apart from a few problems with the foundation, it was some cracking that appeared at the upstream heel of the structure that led to failure of the abutment sections, leaving only the central section intact [5].

The three-dimensional behavior of gravity dams is well described and documented in the technical literature related to their sliding safety assessment [6-14]. In addition to horizontal shear forces, normal and vertical forces are also transmitted through the contraction joints; however, full mechanical interaction is ensured only when shear keys are present.

For example, Osterle et al. [12] applied the "trial-load-twist" method proposed by the USBR [13] to conduct a stability analysis of the Carpenter Dam (height of $36 \mathrm{~m}$ ) by means of a simplified 
3D finite element model composed of vertical cantilever beams, which represented each block, connected with horizontal beams capable of transferring shear forces and torsional moments. Osterle et al. [12] compared these results with those obtained using the gravity method and concluded that for Carpenter Dam, the gravity method is overly conservative.

Lombardi [14], using a parameter referred to as a "local factor," examined a partial model of a dam consisting of nine blocks, with a maximum height of $96 \mathrm{~m}$, resting in a deep valley. According to his method, an individual analysis of each block is first made, and if a block is found to be unstable with respect to sliding, the unbalanced force is transmitted to the adjacent block. In the example presented [14], the gravity method considering the individual blocks on a horizontal foundation plane indicated a sliding safety factor larger (1.85) than that of the connected blocks (1.50). This result is in contrast to the results obtained for the example analyzed by Osterle et al. [12].

This paper presents a simplified limit equilibrium method for performing a 3D structural safety assessment for straight or slightly curved gravity dams on sloped rock foundations. This method takes into account the interaction between monolith blocks through contraction joints. The results were validated using the discrete element code 3DEC [15], which has previously been applied to both static and dynamic analyses of dams, particularly for the assessment of failure mechanisms involving the foundation [16-18].

\section{3D limit equilibrium method for sliding stability}

\subsection{D block interaction and sliding direction}

An important issue related to the effective contact between blocks leading to three-dimensional behavior is the individual sliding trajectory induced by a loading scenario. The sliding trajectory could be unfavorable to this interaction, whereby the base-plane geometry of each block, faults and superficial irregularities on the foundation play an important role. Goodman and Bro [19] conducted a small-scale physical model test of a monolith of Folsom Dam in the USA. Considering the effects of the topography of the contact dam-foundation plane, they conducted two series of direct shear tests, the first with the upper block completely free (an unconstrained case) and the second with the upper block subjected to lateral supports (a constrained case), thereby simulating the presence of adjacent blocks with the wall of the adjacent monolith in contact with the right side of the specimen. The results of the tests were different. When the block was constrained, the shear strength was larger than it was for the unconstrained case. In the unconstrained case, the block exhibited a small rotation along a vertical axis. When the load was increased, the shear resistance of the model reached a peak and then abruptly decreased. The roughness and boundary conditions of the sliding plane was treated numerically using a model developed in $[20,21]$.

As a simple illustration of the problem under consideration, Fig. 1 shows a model of three blocks created with 3DEC [15]. The blocks are deformable, with a modulus of elasticity $(E)$ equal to $50 \mathrm{GPa}$ and a Poisson's ratio (v) of 0.2. The dam foundation contact joints and interblock joints were assumed to have typical values, namely a normal stiffness $\left(K_{n}\right)$ of $40.5 \mathrm{GPa} / \mathrm{m}$ and a shear stiffness $\left(K_{s}\right)$ of $16.2 \mathrm{GPa} / \mathrm{m}$ with no cohesion and a $45^{\circ}$ friction angle. The blocks were subjected to self-weight, hydrostatic pressure (corresponding to the crest height) and uplift pressure using a bilinear spatial distribution with a $2 / 3$ reduction at the drainage curtain. Sliding was induced by progressively reducing the friction angle. Individual displacement directions were plotted for each block for the cases of independent and interacting behaviors (Fig. 1). In this latter case, the trajectories became parallel. The structure composed of interacting blocks behaved as a whole structure, with the smaller blocks (Nos. 1 and 2) on the steeper slope pushing against the third block.

Another important issue in stability assessment is the arching effect that takes place, even in the case of straight gravity dams $[22,23]$, which is an aspect that has long been the subject of controversy [24]. The arch effect improves the behavior of the structure when the foundation can withstand the resultant thrust.

Another issue that should be addressed is the resistance of shear keys and their capacity to overcome high concentrated stresses. Curtis and Lum [25] suggested a no-tension Mohr-Coulomb model to assess the strength of shear keys. Although no tensile stresses can be transmitted across shear keys, these keys can maintain a residual shear resistance due to a cohesive component. In the case of a large strength of the shear keys, the ultimate load may be controlled by weakness at the abutments.

Finally, for dams located in northern regions where seasonal temperature variations are important, contraction joints might be tightly closed in the summer, corresponding to a monolithic 3D behavior. However, contraction joint opening in winter may limit the ability to transfer forces from one block to another [26,27].

\subsection{Proposed method: introductory two-block example}

The 3D limit equilibrium method proposed in this paper follows a sequential scheme through the analysis of each block as an individual element. The interaction between blocks in each step is established on the basis of the potential sliding failure mechanism that is accepted as the most probable. This method is somewhat
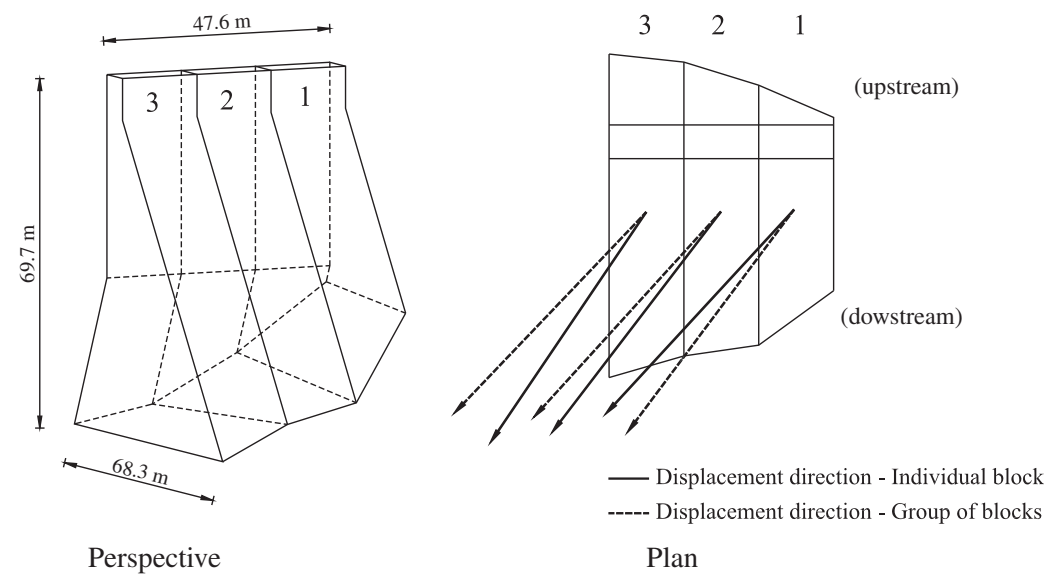

Fig. 1. Displacement directions for each independent block computed using individual and global models (obtained using a 3DEC model). 


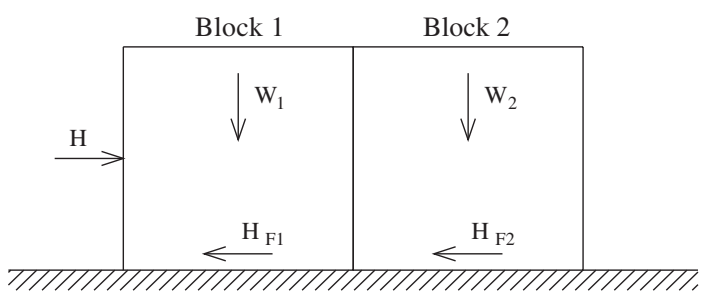

Fig. 2. Limit equilibrium of two adjacent blocks.

similar to the method devised by Lombardi [14], but it is able to analyze the full sliding of each block in three dimensions rather than only in the abutment-valley direction. In addition, it accepts the transmission of tangential and normal components of contact forces through contraction joints, rather than just the tangential component as proposed in [14].

To properly explain the principles adopted in this study, a simple example in a 2D plane (Fig. 2) is first presented. In this example, two blocks are shown to withstand the horizontal load $H$ applied to block 1 . Block 1 will initially bear this load alone through a horizontal friction force $\left(H_{F 1}\right)$ according to its self-weight $\left(W_{1}\right)$ and the friction angle $(\phi)$ at its base:

$H_{F 1}=W_{1} \operatorname{tg} \phi$

A sliding safety factor $\left(S S F_{1}\right)$ may be defined, where values above 1.0 indicate that block 1 can withstand the horizontal load $H$ by itself.

$\mathrm{SSF}_{1}=\frac{H_{F 1}}{H}$

Consider now the case where $S S F_{1}<1.0$, such that $H_{F 1}<H$. This means that block 1 is not able to bear the load $H$ alone and will share this responsibility with block 2 . To determine the overall safety factor $\left(S S F_{g}\right)$, an interactive process is proposed. For each step $i$, an increasing factor $f_{i}$ is adopted and applied to reduce the resistance force. The cycle begins with the determination of the force that is transmitted from block 1 to block $2\left(R_{1, i}\right)$, in accordance with the current $f_{i}$ :

$R_{1, i}=\frac{H_{F 1}}{f_{i}}-H$

Because block 1 does not withstand the load $H$ alone, the value of $R_{1, i}$ is negative. The resultant of the forces acting on block $2\left(R_{2, i}\right)$ is determined by
$R_{2, i}=\frac{H_{F 2}}{f_{i}}-\left|R_{1, i}\right|$

where $H_{F 2}$ is the horizontal friction force of block 2, given by

$H_{F 2}=W_{2} \operatorname{tg} \phi$

where $W_{2}$ is the self-weight of block 2 . When, for a given value of $f_{i}$, $R_{2, i}$ is negative, the two-block system is no longer stable with respect to the global sliding mechanism, so the previous value of $f_{i}$, $f_{i-1}$, should be taken as the global sliding safety factor $\left(S S F_{g}\right)$. This principle is extended in the $3 \mathrm{D}$ analysis, in which the treatment of applied loads is obviously much more complicated.

\subsection{Analysis of an individual block}

Each block, assumed to behave as a rigid body, is geometrically defined by 12 points (Fig. 3 ). This assumption is valid in most practical cases, but the method may of course be applied to more general geometries. The following loads, defined in a global coordinate system $\left(F_{x y z}\right)$, are considered: self-weight $(W)$; hydrostatic pressure $(H P)$ acting in the upstream-downstream, vertical and horizontal directions; uplift force $(U)$; and ice load $(I)$. Depending on the effectiveness of the drainage system in the foundation and the position of the gallery, the uplift force can be applied with a reduction factor. The total load $F_{x y z}$ is composed of three components, $F_{x}, F_{y}$ and $F_{z}$, according to the global coordinate system $x y z$. The shear strength of the foundation joint is governed by the Mohr-Coulomb criterion, defined by a friction angle and cohesion value, while tension is not allowed to develop along the dam foundation interface.

The loads are then computed using a local coordinate system $\left(F_{123}\right)$, according to Eqs. (6) and (7), established along the base surface of the block, defined by the upstream-downstream $(\beta)$ and abutment/valley $(\alpha)$ inclinations (Fig. 4 ). The total load $F_{123}$ is composed of three components, $F_{1}, F_{2}$ and $F_{3}$, according to the local coordinate system 123.

$F_{123}=M F_{x y z}$

$M=\left[\begin{array}{ccc}\cos \beta & \sin \alpha \sin \beta & -\cos \alpha \sin \beta \\ 0 & \cos \alpha & \sin \alpha \\ \sin \beta & -\sin \alpha \cos \beta & \cos \alpha \cos \beta\end{array}\right]$

Following this scheme, two safety factors can be determined. The first (Eq. (8)) is related herein to a single block moving in the direction of the loads resultant on the foundation surface, leading

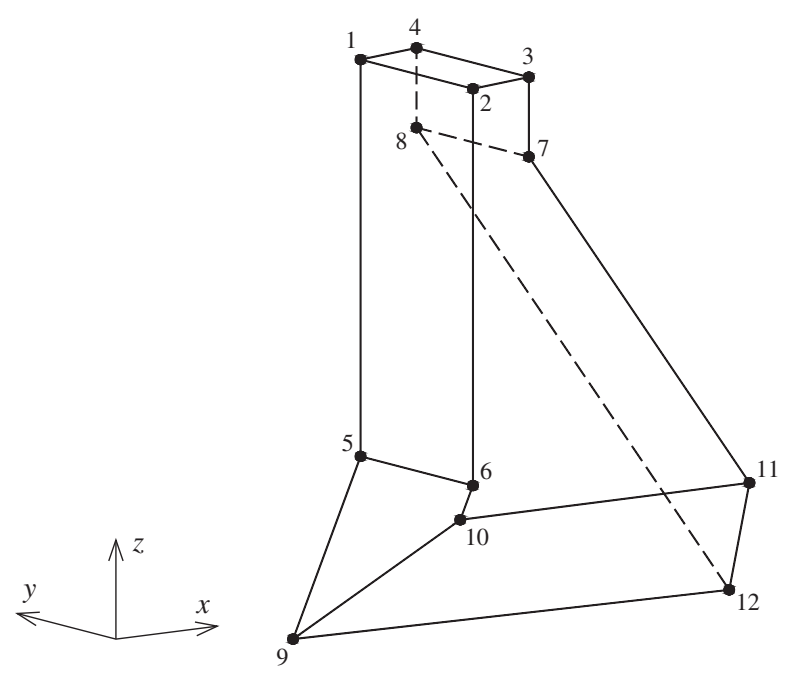

Fig. 3. Block geometry.
Data file:

11 ; label
42.9434 ; headwater level
6.7556 ; gallery position
0.667 ; drainage effectiveness
0 ;ice load
1.581715 .850042 .9434 ;point 1
1.58170 .000042 .9434 ;point 2
8.69370 .000042 .9434 ;point 3
8.693715 .850042 .9434 ;point 4
1.581715 .85003 .1634 ;point 5
1.58170 .00003 .1634 ;point 6
8.69370 .000034 .8634 ;point 7
8.693715 .850034 .8634 ;point 8
$-6.809215 .8500-13.6184$;point 9
0.00000 .00000 .0000 ;point 10
$36.59010 .0000-2.3318$;point 11
$48.095615 .8500-17.6724$;point 12

11 ;label

0 ;ice load

8.69370 .000042 .9434 ;point 3

8.693715 .850042 .9434 ;point 4

8.69370 .000034 .8634 ;point 7

8.693715 .850034 .8634 ;point 8

$-6.809215 .8500-13.6184$;point 9

$36.59010 .0000-2.3318$;point 11

48.095615 .8500 - 17.6724 ;point 12 


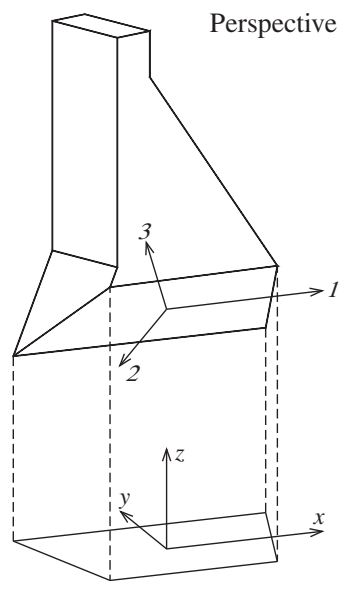

View
(upstream)

Cross section (upstreat)
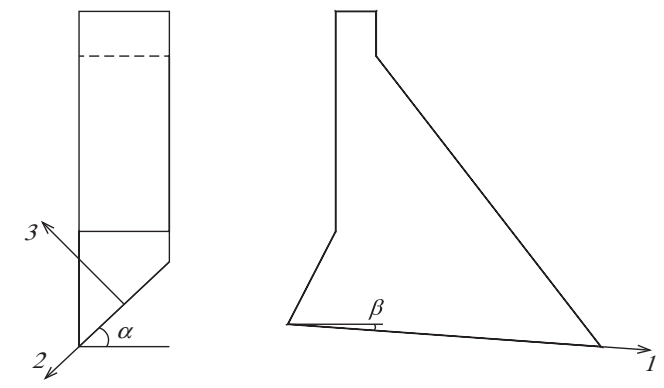

Fig. 4. Coordinate transformation between the global system (xyz) and the local system (123).

(a) $\alpha=10^{\circ}$, Cohesion $=0, \phi=45^{\circ}$

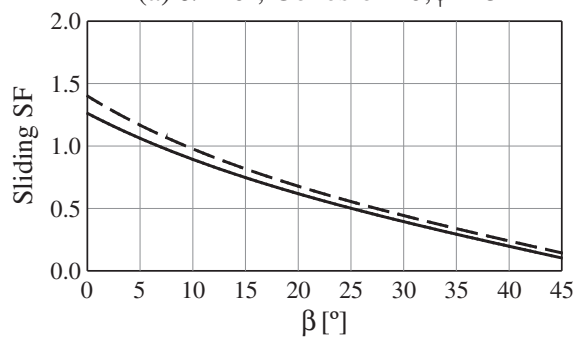

(b) $\alpha=10^{\circ}$, Cohesion $=329 \mathrm{kPa}, \phi=55^{\circ}$

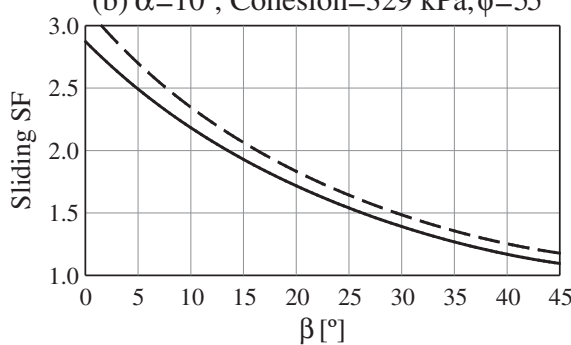

$S S F_{u}$ - Unconstrained condition

- - - $S S F_{c}$ - Constrained condition (monolith interaction) (c) $\beta=10^{\circ}$, Cohesion $=0, \phi=45^{\circ}$

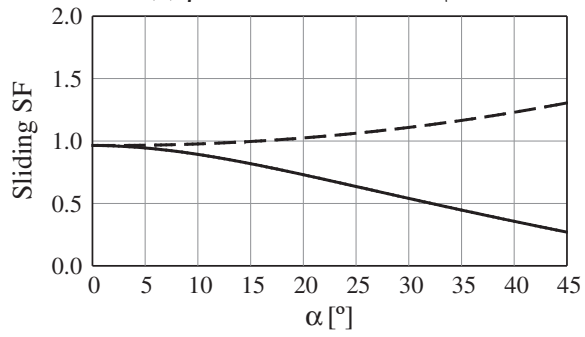

(d) $\beta=10^{\circ}$, Cohesion $=329 \mathrm{kPa}, \phi=55^{\circ}$

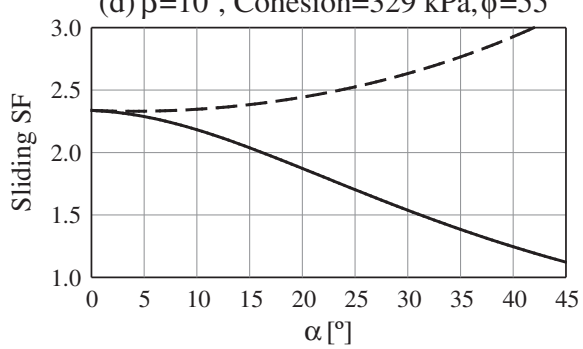

$\alpha$ : abutment/valley direction

$\beta$ : upstream/dowstream direction

Fig. 5. Parametric analysis of $\beta\left[^{\circ}\right.$ ] for (a) $\alpha=10^{\circ}$, cohesion $=0$, and $\phi=45^{\circ}$ and for (b) $\alpha=10^{\circ}$, cohesion $=329 \mathrm{kPa}$, and $\phi=45^{\circ}$. Parametric analysis of $\alpha\left[{ }^{\circ}\right.$ ] for (c) $\beta=10^{\circ}$, cohesion $=0$, and $\phi=45^{\circ}$ and for (d) $\beta=10^{\circ}$, cohesion $=329 \mathrm{kPa}$, and $\phi=45^{\circ}$.

to the unconstrained condition $\left(S S F_{u}\right)$. The second safety factor (Eq. (9)) is related to a single block moving in the upstream-downstream direction and constrained by adjacent monoliths $\left(S S F_{c}\right)$ :

$\operatorname{SSF}_{u}=\frac{-F_{3} \operatorname{tg} \phi+c A_{c}}{\sqrt{F_{1}^{2}+F_{2}^{2}}}$

$S S F_{c}=\frac{\left(-F_{3} \cos \alpha-F_{2} \sin \alpha\right) \operatorname{tg} \phi+c A_{c}}{F_{1}}$

where $c$ is the cohesion and $A_{c}$ is the compressed area of the base.

The effects of the foundation surface orientation, defined by the parameters $\alpha$ and $\beta$, on the safety factors given by Eqs. (8) and (9) may be illustrated by performing parametric analyses. The initial model, whose dimensions are defined in the data file attached to the figure, corresponds to the example shown in Fig. 3. When $\alpha$ and $\beta$ are changed, the initial geometry also changes. The forces considered include the self-weight, the hydrostatic pressure on the upstream face and the uplift pressure. The drainage system is located next to the upstream face and imposes a $2 / 3$ reduction in the value of the uplift pressure.

The friction angle and cohesion at the concrete-rock interface are indicated in Fig. 5. Regarding the variation in the upstreamdownstream direction, increasing the angle $\beta$ causes a reduction of $S S F_{u}$ and $S S F_{c}$, both for the model with cohesion (Fig. 5b) and for the model without cohesion (Fig. 5a). For the other direction, namely the abutment-valley inclination, increasing the $\alpha$ angle while maintaining a constant $\beta$ angle $\left(10^{\circ}\right)$ causes a reduction in $S S F_{u}$, but $S S F_{c}$ increases (Fig. $5 c$ and d). When $\alpha$ is changed, the initial geometry is changed, and both the self-weight and hydrostatic pressure increase. The $S_{S} F_{c}$ is more sensitive to the self-weight than to the hydrostatic pressure. The addition of the uplift force does not play any role in this constrained case because the projection in the plane that takes the upstream-downstream direction into account is unchanged. 


\subsection{Analysis of a set of blocks}

To conduct a global analysis of a set of blocks, an iterative computation scheme was implemented, similar to the wedge method proposed in $[28,29]$, and is illustrated using the introductory example (Fig. 2). According to a predicted failure sequence, which often occurs from the abutment to the valley, the blocks were analyzed based on the unconstrained condition and by considering a reduction factor $(R F)$ of the strength parameters of the current calculation step. This factor plays the same role as that played by the $f_{i}$ factor in the introductory example (Fig. 2). For narrow valleys, the natural load transmission occurs in the abutment-valley direction, but this significant factor should be carefully examined for each particular case.

For each block, the applied forces are compared to the resistance capacity of the dam-foundation interface. When the capacity is greater than the driving loads, the block is considered stable by itself, and no load is transmitted to the adjacent block. Otherwise, if the driving loads reach the dam-foundation strength capacity, the unbalanced force $\left(U F_{x y z}\right)$ from Eqs. (10) and (11) is transmitted to the adjacent block on the valley side. The new conditions for the stability of the block that received the overload are assessed. The analysis continues by increasing $R F$ until the last block fails.

$U F_{123}=\frac{-F_{3} \operatorname{tg} \phi}{R F}+\frac{c A_{c}}{R F}-\sqrt{F_{1}^{2}+F_{2}^{2}}$

$U F_{x y z}=M^{-1} U F_{123}$

The calculation cycle is shown in Fig. 6. In this figure, step [1] represents the determination of the loads related to each block. These loads are the self-weight $\left(F_{W}\right)$ due to the geometric and material properties of the block, the hydrostatic pressure $\left(F_{H}\right)$, the uplift $\left(F_{U}\right)$ and the ice thrust $\left(F_{I}\right)$. These forces are determined in the global system and are added to compute the resultant force
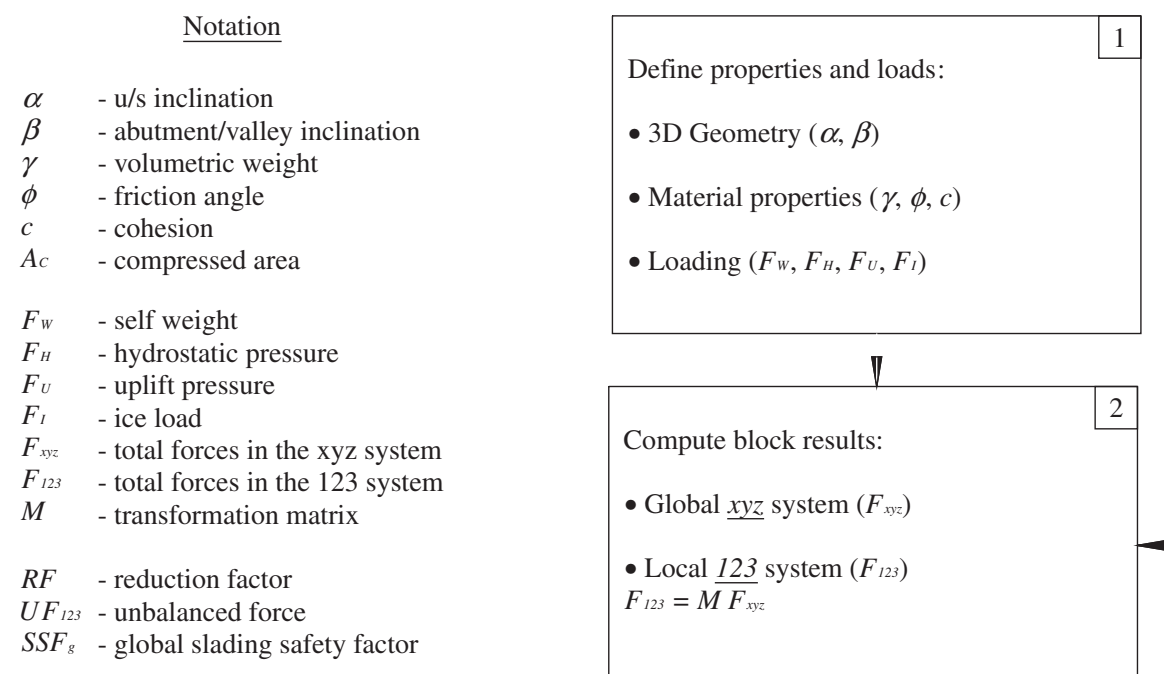

- Global $x y z$ system $\left(F_{x y z}\right)$

- Local 123 system $\left(F_{123}\right)$

$F_{123}=\overline{M F_{x y z}}$

$\underline{\text { Blocks interaction }}$

$F_{x y z}=F_{x y z}+U F_{x y z}$

Check block self resistance for a

reduction factor $R F$ :

- Unbalanced force ( $\left.U F_{123}\right)$

$U F_{123}=\frac{-F_{3} \operatorname{tg} \phi}{R F}+\frac{c A_{c}}{R F}-\sqrt{F_{1}^{2}+F_{2}^{2}}$

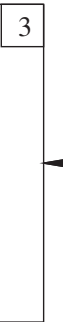

$R F=0.01,0.02, \ldots$

- Final Sliding Safety Factor $\left(S S F_{g}\right)$ :

$S S F_{g}=R F$
$U F_{123}<0$

Instable block

\section{1}

\section{II}

- No force will be transmited to adjacent block

- New interaction with next incremental

$R F$ value
- Unbalanced force will be transmited to adjacent block

- Compute unbalanced force in the global $\underline{x y z}$ coordinate system $U F_{x y z}=M^{-1} U F_{123}$ 

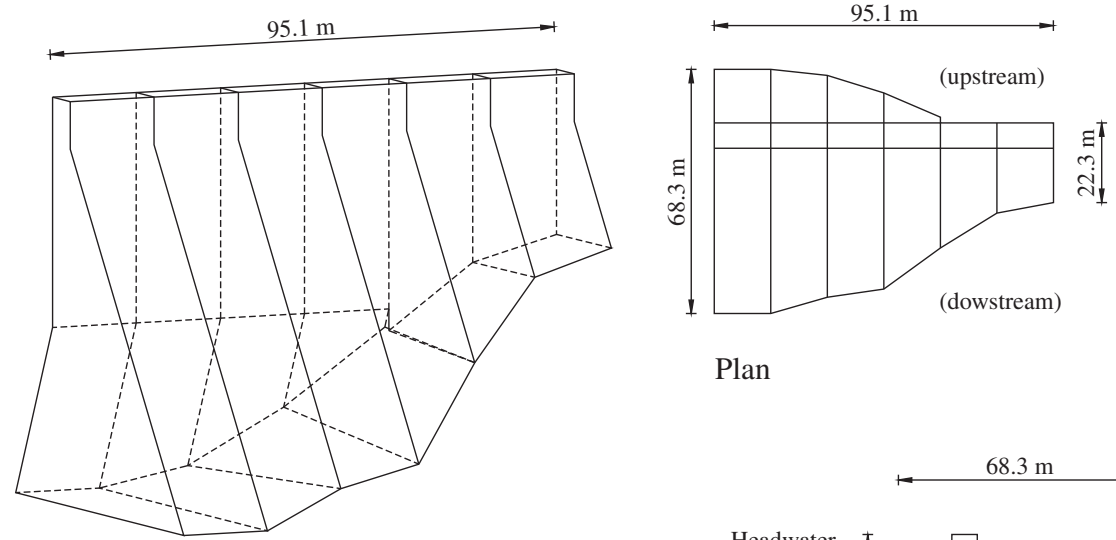

Plan

Perspective
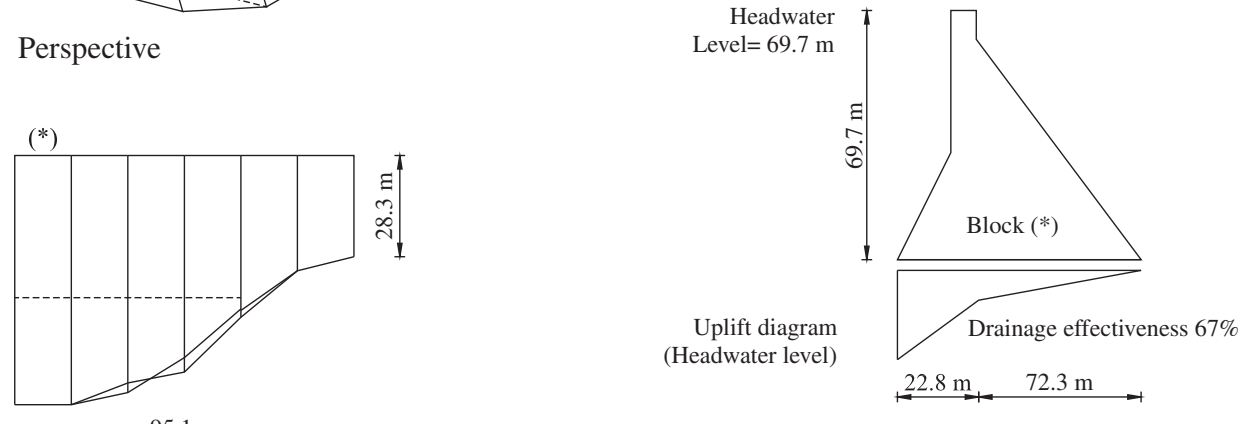

Elevation (dowstream side)

Section

Fig. 7. Geometric definition existing dam A.

(Fig. 6 [2]) for each block. This resultant force, $F_{x y z}\left(F_{x}, F_{y}, F_{z}\right)$, will be transformed to the local system associated with the base plane orientation of each block, giving rise to the force $F_{123}\left(F_{1}, F_{2}, F_{3}\right)$. Based on the local system of axes, the block will be checked in terms of stability, and the unbalanced force $\left(U F_{123}\right)$ to be transmitted to the adjacent block will be determined. If $U F_{123}$ is positive, the block
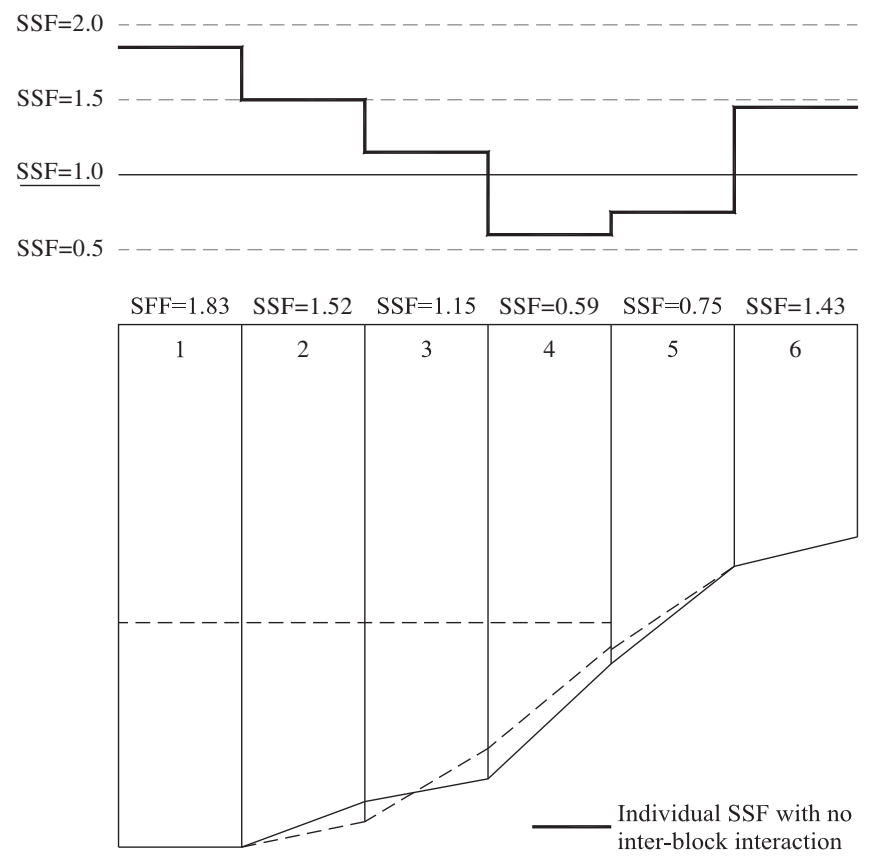

Fig. 8. Individual sliding safety factors (SSFs) for dam A for the case in which interblock interactions are not considered. is stable (Fig. 6 [4a]). In this case, $U F_{123}$ represents the strength reserve for the sliding scenario. If $U F_{123}$ is negative, the unbalanced force must be transmitted to the adjacent block, according to the sequence of failure established, after being transformed to the global system $\left(U F_{x y z}\right)$ (Fig. 6 [4b]). The calculation continues until an overall failure of the model occurs, in which case the unbalanced

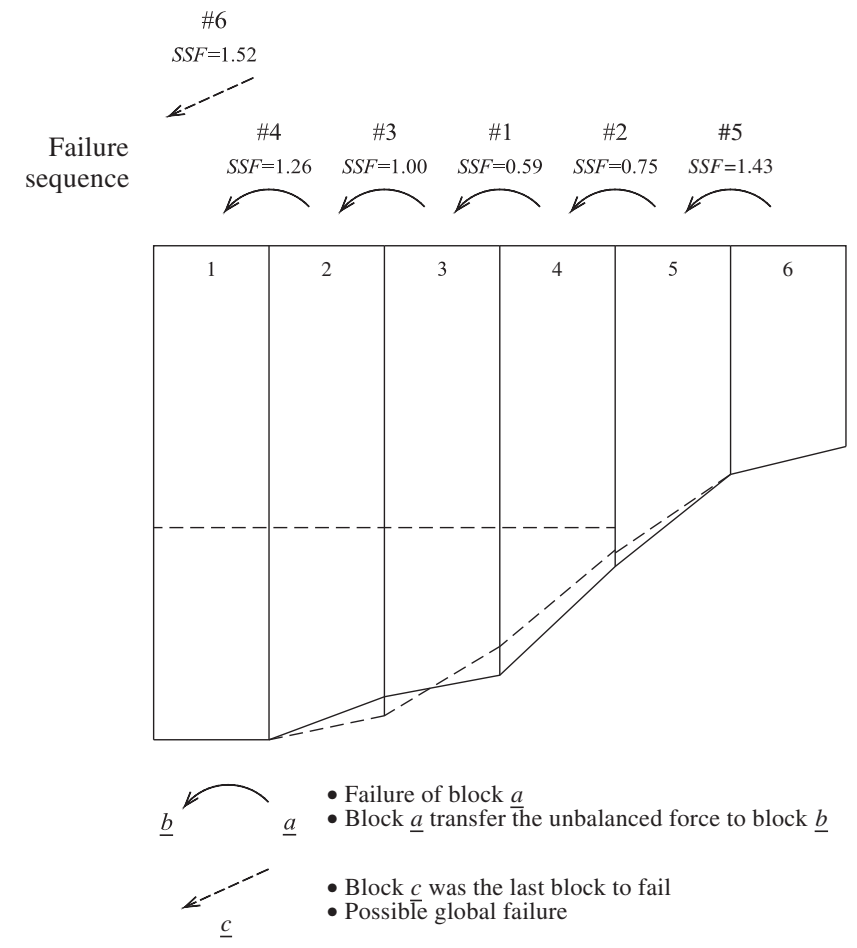

Fig. 9. Individual and global sliding safety factors (SSFs) and failure sequence for dam A when taking into account interblock interactions. 


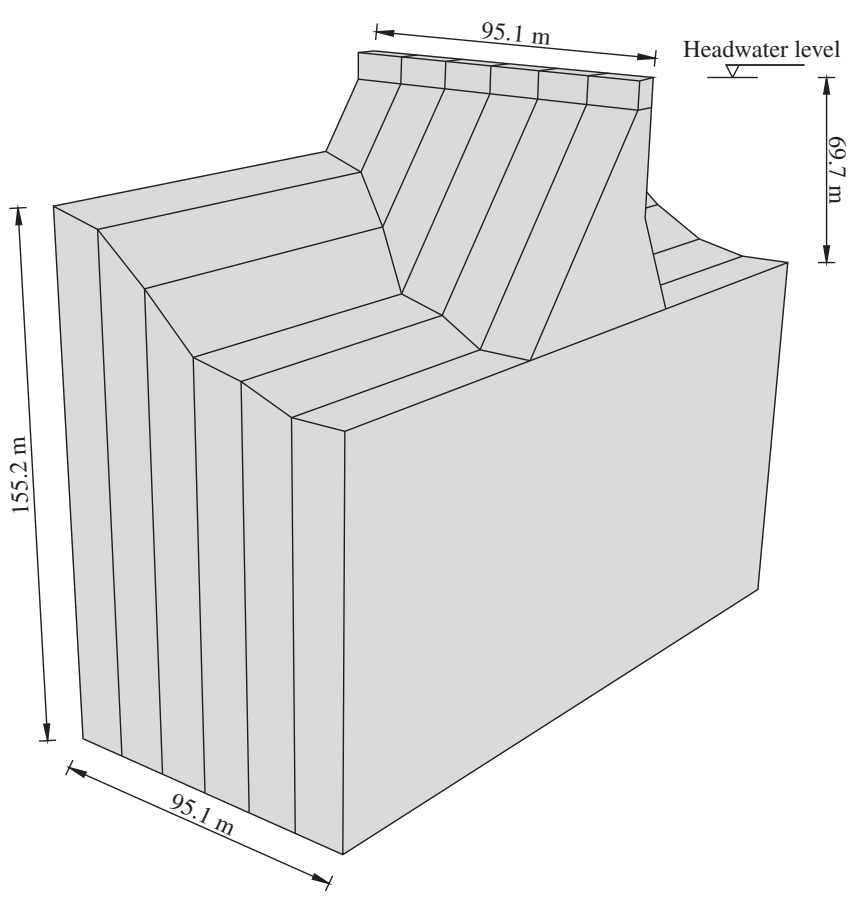

Fig. 10. 3DEC model of dam A.

force $\left(U F_{x y z}\right)$ for all of the blocks is negative. The $R F$ corresponding to the last stable value reached is designated as the sliding safety factor (SSF), as in the initial example.

Some comments related to the method described are given below:

(i) The foundation reaction force at the base of the block is assumed to be in the same direction as the resultant of the applied loads to the block such that the unbalanced force is computed as the difference between them. (ii) The vertical component of the unbalanced force is not transmitted to the adjacent block and is assumed to be transmitted to the foundation. Otherwise, this component would contribute to the sliding safety factor of the adjacent block.

(iii) It is assumed that the unbalanced load could be transferred between the blocks either through friction or through the presence of shear keys. This limitation should be verified for the particular dam analyzed.

\subsection{Example of a set of blocks}

The method described above was applied to dam A in Fig. 7, which is a partial model of an existing dam composed of six blocks with a maximum height of $69.7 \mathrm{~m}$. The blocks were subjected to self-weight, hydrostatic pressure (corresponding to the crest height) and uplift pressure using a bilinear spatial distribution with a 2/3 uplift pressure reduction due to the drainage curtain. The movement of block 1 was not restricted in any direction. The block could move in the upstream-downstream direction as well as in the abutment-valley direction.

As a reference method, a 3DEC (Fig. 10) analysis was conducted by progressively reducing the joint (dam-foundation contact) friction angle from $\phi=45^{\circ}$ and assuming a constant normal stiffness $\left(K_{n}=40.5 \mathrm{GPa} / \mathrm{m}\right)$ and shear stiffness $\left(K_{s}=16.2 \mathrm{GPa} / \mathrm{m}\right)$. This model uses deformable blocks, i.e., blocks discretized into a coarse internal mesh of elastic tetrahedra $(E=50 \mathrm{GPa}, v=0.2)$ subjected to self-weight, hydrostatic pressure and uplift pressure. The boundary conditions were applied to the foundation block, thereby restraining displacements of the external faces in the normal direction. The global safety factor obtained with $3 \mathrm{DEC}$ was $\mathrm{SSF}_{\mathrm{g}}=1.5$.

Using the proposed methodology, the safety factors for individual blocks were first determined in the absence of any interaction between blocks using a dam-foundation interface friction angle of $45^{\circ}$. The values obtained are shown in Fig. 8 . The block with the lowest safety factor was block $4\left(S S F_{u}=0.59\right)$, and the block with the highest safety factor was block $1\left(S_{S F}=1.83\right)$. Fig. 9 shows the safety factors determined for the case in which there were

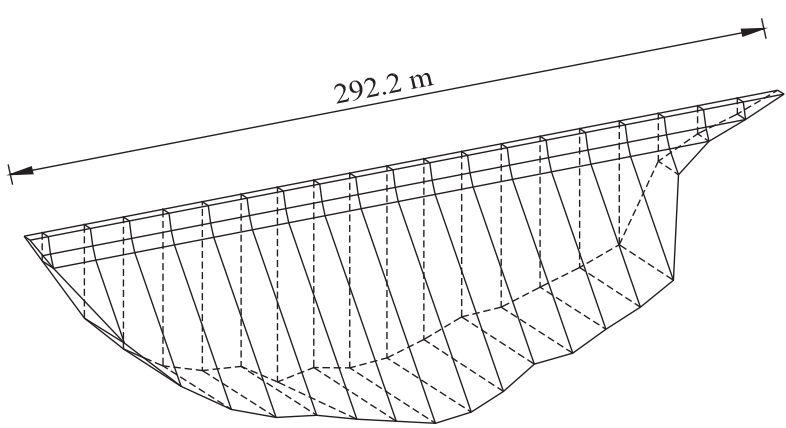

Uplift diagram (Headwater level)

Perspective
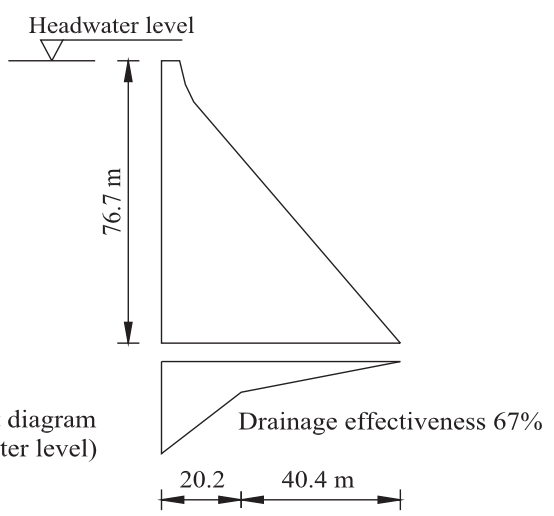

Section

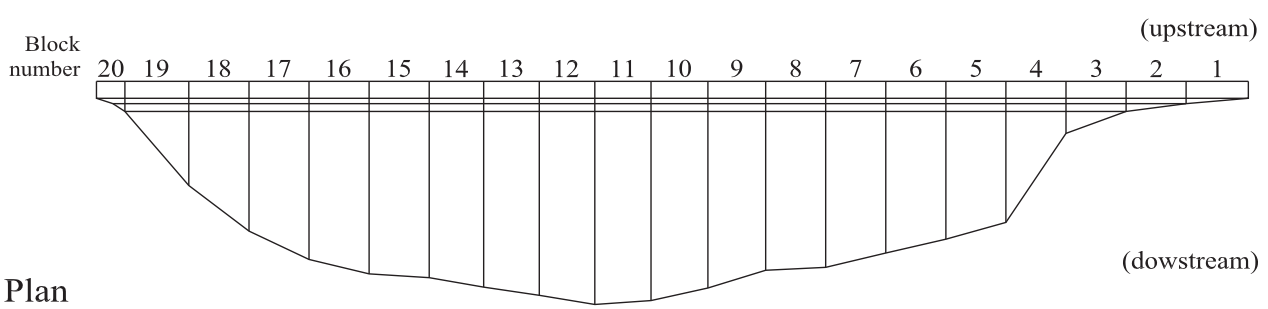

Fig. 11. Geometry of dam B for limit equilibrium validation. 
interactions between the blocks. The first block to reach its sliding limit state was still block 4 , with the same $S S F_{u}$, indicating that failure occurs in the absence of interactions with any other block. This is similar to what occurred with blocks 5 and 6 , which also had the same safety factors for the scenario in which no interactions were present. The other blocks exhibited significant reductions in their safety factors. For example, block 1 , which had a $S S F_{u}$ of 1.83 , had a $S S F_{u}$ of 1.52 when interactions were considered.

Fig. 9 presents a summary of the values obtained as well as the load transfer sequence. The first block to "collapse," or reach its limit state, was block $4\left(S F_{u}\right.$ of 0.59$)$, followed by blocks 5 $\left(S S F_{u}=0.75\right), 3\left(S S F_{u}=1.00\right), 2\left(S S F_{u}=1.26\right), 6\left(S S F_{u}=1.43\right)$ and finally $1\left(S S F_{u}=1.52\right)$. Based on these results, the possible failure mechanism is the global sliding of all dam blocks (Fig. 9). The global safety factor $\left(S F_{g}\right)$ is assumed to be 1.52 , which closely matches the result obtained from the 3DEC analysis.

\section{Case study}

An existing concrete gravity dam (dam B, Fig. 11) located in Canada, which is comprised of 19 monoliths and has a width of approximately $15 \mathrm{~m}$, a maximum height of $80 \mathrm{~m}$ and a crest length of $288 \mathrm{~m}$, was analyzed using the proposed 3D limit equilibrium method. A water level corresponding to the dam height and a bilinear uplift pressure spatial distribution were assumed. The forces considered were the self-weight, the hydrostatic pressure on the upstream face and the uplift pressure. For the dam-interface contact, a null cohesion and an initial friction angle of $45^{\circ}$ were adopted.

A numerical analysis was carried out with a 3DEC model (Fig. 12). The blocks were deformable ( $E=50 \mathrm{GPa}, v=0.2$ ) and characterized by foundation-dam interactions and interblock joints $\left(K_{n}=40.5 \mathrm{GPa} / \mathrm{m}, K_{s}=16.2 \mathrm{GPa} / \mathrm{m}\right)$ with a frictional strength $(\phi$ $=45^{\circ}$ ) and no cohesive forces. The loads considered were selfweight, hydrostatic pressure on the upstream face and uplift pressure on the foundation joint. The boundary conditions were similar to those of the previous 3DEC model; namely, vertical displacements were restrained at the model base, and horizontal displacements were restrained in the direction normal to the lateral boundaries. This 3DEC model predicted a global safety factor of 1.40 .

The results of the proposed method and the load transfer sequence are shown in Fig. 13. The "collapse" sequence is similar for both abutments. In the right abutment, the collapse sequence is blocks $19,18,17,16,15,14,13$ and 12 . In the left abutment, collapse starts with block 4 , followed by blocks 5, 6, 9, 7, 10 and 8 . The last block to fail is block 11 (SSF of 1.43). The possible failure mechanism corresponds to global sliding of all blocks. The SSF value of 1.43 was defined as the global safety factor of the full structure $\left(S S F_{g}\right)$ and is in excellent agreement with the value obtained from the 3DEC model (1.40).

Safety factors $\left(S S F_{2 D}\right)$ were also determined using the conventional gravity method. Sliding is only allowed to take place in the upstream-downstream direction leading to a constrained condition. Because the dam presents similarities between the $2 \mathrm{D}$ versus 3D stability analysis in terms of its cross-sections, the $S S F_{2 D}$ is equal to 1.3 for the majority of blocks, with the exception of block $3\left(S S F_{2 D}=1.7\right)$ and block $19\left(S S F_{2 D}=1.7\right)$. For blocks with a marked inclined foundation, it is possible to observe a significant disparity between the results from the 2D analysis and those from the 3D analysis. For example, the $S S F_{u}$ is 0.27 for block 4 (Fig. 13), and the $S S F_{2 D}$ is 1.3. For block 11, the last block to fail in the 3D analysis, the $S S F_{2 D}$ is also equal to 1.3. This is less than the value computed in the $3 \mathrm{D}$ analysis, namely $\mathrm{SSF}_{u}=1.43$. For block 11 , the $2 \mathrm{D}$ gravity method is more conservative, as would be expected for a simplified method. For an unusual or extreme load combination, and assuming that interactions between blocks are effective, the failure could occur along the abutments through the most sensitive blocks.

\section{Summary and conclusions}

This paper presents a general 3D limit equilibrium method for conducting a sliding safety assessment of concrete gravity dams subjected to hydrostatic loads with monoliths resting on sloped rock foundations. The method is able to take into account arbitrary three-dimensional variations in cross-sections, with the dam-foundation contact plane sloping in the upstream-downstream and abutment-valley directions. The classical no-tension Mohr-Coulomb model was adopted to compute the shear strength that could be mobilized along the dam foundation interface. In its present form, the method assumes that compressive and unbalanced shear loads could be transferred between adjacent monoliths. The sliding responses of two existing gravity dams were computed using the proposed method, leading to the computation of global sliding

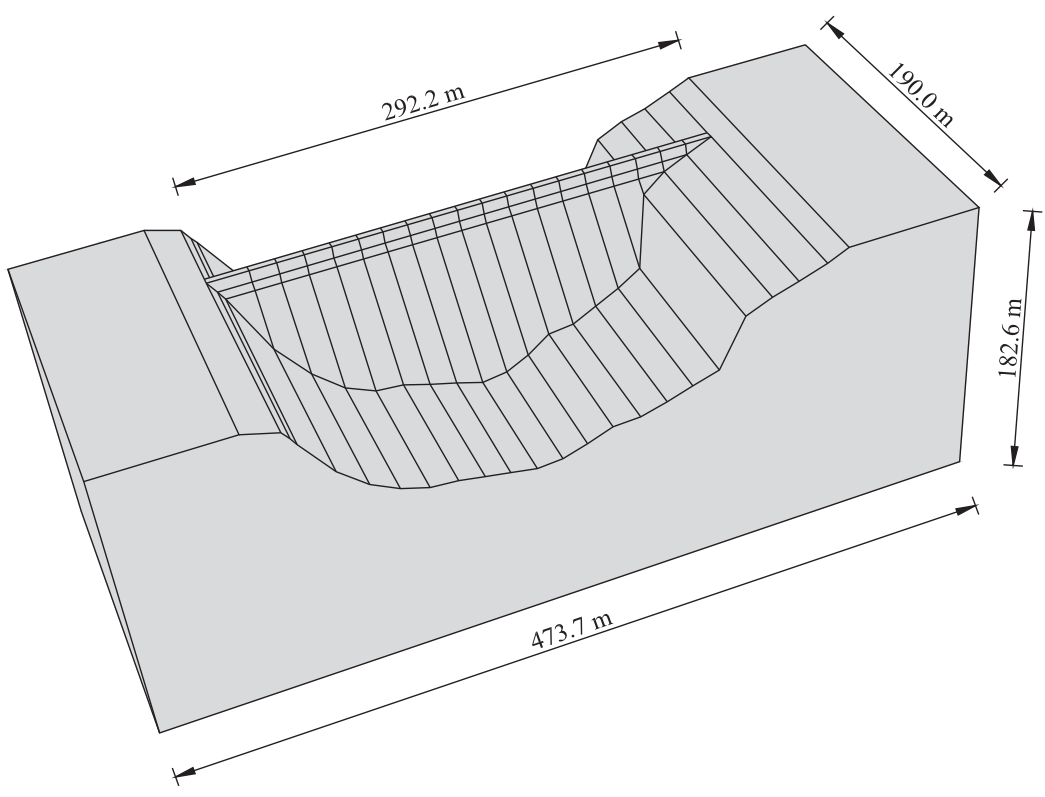

Fig. 12. 3DEC model of dam B. 
E.M. Bretas et al./Computers and Geotechnics 44 (2012) 147-156

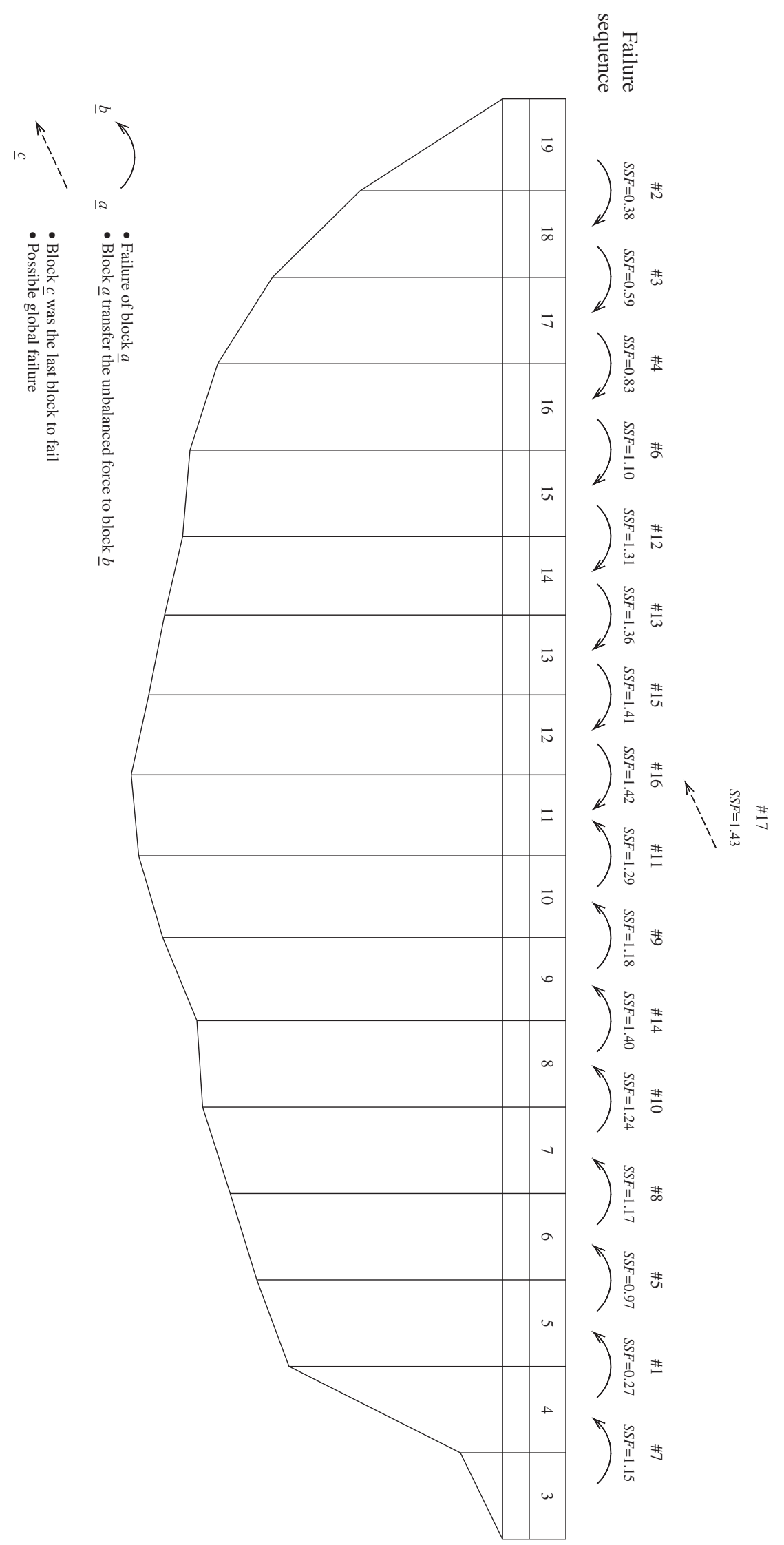

Fig. 13. Stability analysis and failure sequence for dam B. 
safety factors $\left(S F_{g}\right)$ that were nearly identical to those obtained from more elaborate 3D analyses using the distinct element (DE) method. The main conclusions of this study can be summarized as follows:

(i) The proposed method is simple to implement, and comparisons with results from 3D numerical analyses indicate that it produces accurate results. It is a powerful tool with which practicing engineers can perform preliminary analyses prior to conducting 3D numerical (FE or $\mathrm{DE}$ ) analyses that require significant resources and expertise.

(ii) For the two existing dams analyzed, the sequence of load transfer to adjacent monoliths is initiated from the monolith resting on the plane with the largest abutment-valley inclination angle.

(iii) A dam composed of individual monoliths that do not possess sufficient strength when considered as isolated structures can be shown to be a stable assembly when load-sharing capabilities of the monoliths are considered in the stability analysis.

A limitation of the proposed method is that it assumed the presence of compressive and shear load transfer capabilities of the monoliths. 3D studies that consider different initial contraction joint openings are the next step in assessing the effect of kinematic interactions among sliding blocks, which produce a potential wedge effect that creates a new state of static equilibrium.

\section{Acknowledgments}

The financial support provided by FCT (the Portuguese Foundation for Science and Technology), through the PhD Grant SFRH/BD/ 43585/2008, and by the Natural Science and Engineering Research Council of Canada is acknowledged.

\section{References}

[1] Léger P, Tinawi R, Bhattacharjee SS, Leclerc M. Failure mechanisms of gravity dams subjected to hydrostatic overload: influence of weak lift joints. In: ICOLD XIX congress on large dams, Florence, Italy; 1997. p. 11-38.

[2] Bretas EM, Lemos JV, Lourenço PB. Masonry gravity dams - a numerica application for stability analysis. In: 8th International masonry conference, Dresden, Germany; 2010.

[3] Lombardi G. Concrete dams and their foundation. Evaluation for static loading. In: Kreuzer et al., editor. International workshop on dam safety evaluation, Sutton, UK; 1993. p. 77-90.

[4] Murthy YK, Mane PM, Pant B. Tensile failures in some stone masonry gravity dams in India. In: 13th ICOLD congress, New Delhi, India; 1979. p. 461-77.

[5] Rogers JD. Lessons learned from the St. Francis dam failure. Geo-Strata. Reston: ASCE; 2006. p. 14-7.
[6] Tinawi R, Léger P, Ghrib F, Bhattacharjee S, Leclerc M. Structural safety of existing concrete dams: influence of construction joints. Report to the Canadian Electrical Association (CEA) Montreal. Department of Civil Engineering, École Polytechnique; 1998.

[7] Ruggeri G. Sliding safety of existing gravity dams. ICOLD European, Group; 2004.

[8] Schleiss AJ, Pougatsch H. Les Barrages - Du projet à la mise en service. (Dams from project design to operation - in French) Lausanne, Switzerland: Presse Polytechniques et Universitaires Romandes; 2011.

[9] Sun GH, Zheng H, Liu DF. A three-dimensional procedure for evaluating the stability of gravity dams against deep slide in the foundation. Int J Rock Mech Min Sci 2011:48:421-6.

[10] Campbell JS, Zienkiewicz OC. Gravity dam analysis: the effect of valley width. In: International symposium on criteria and assumptions in numerical analysis of dams, Swansea, UK; 1975. p. 1007-31.

[11] Lund GS, Boggs H. Soda Dam: three-dimensional analysis of a concrete gravity dam. In: USCOLD, editor. Lessons learned from the design, construction and operation of dams and reservoirs, Denver, USA; 1993. p. 65-82.

[12] Osterle JP, Bazant E, Rizzo PC, Weatherford C. Three-dimensional stability analysis of Carpenter Dam. Geotechnical practice in dam rehabilitation. Raleigh, USA: ASCE, Geotechnical Special Publication; 1993. p. 86-99.

[13] USBR. Design of gravity dams, 3rd ed. Denver, USA; 1987.

[14] Lombardi G. 3-D analysis of gravity dams. Hydropower \& Dams; 2007. p. 98 102.

[15] Itasca. 3DEC - 3 dimensional distinct element code - theory and background. Minneapolis, USA: Itasca Consulting Group, Inc.; 2007.

[16] Lemos JV. Discrete element analysis of dam foundations. In: Sharma VM, Saxena KR, Woods RD, editors, Distinct element modelling in geomechanics, Balkema, Rotterdam; 1999. p. 89-115.

[17] Lemos JV. Block modeling of rock masses. Concepts and application to dam foundations. Eur J Environ Civil Eng 2008;12(7-8):915-49.

[18] Lemos JV, Antunes NS. Modelling of arch dam foundation failure scenarios case studies of Baixo Sabor and Alto Ceira dams. Dam Eng 2011;XXI(4):299-312.

[19] Goodman RE, Bro A. Shear strength of a foundation with two dimensional roughness. In: 40th US symposium on rock mechanics, Anchorage, USA; 2005.

[20] Galic D, Glaser SD. Outline of a method for determining the three dimensional failure route of a sliding block. In: 40th US symposium on rock mechanics, Anchorage, USA; 2005.

[21] Galic D, Glasser SD, Goodman RE. Calculating the shear strength of a sliding asymmetric block under varying degrees of lateral constrain. Int J Rock Mech Min Sci 2008;28(8):1287-305.

[22] Herzog MAM. Spatial action of straight gravity dams in narrow valleys. ASCE J Struct Eng 1989;115(3):698-706.

[23] Fanelli M, Mazzà G, Ruggeri G. Gravity dams: safety evaluation against sliding with a 3-D rigid body formulation. Research and development in the field of dams. Crans-Montana, Switzerland; 1995. p. 253-64.

[24] Jakobsen BF. Arching not effective in slightly arched gravity dams. Eng News Record 1924;92(24):1020-3.

[25] Curtis DD, Lum KKY. Estimated strength of shear keys in concrete dams. In: CDA (Canadian Dam Association) 2008 annual conference, Winnipeg, Canada; 2008. p. $17-28$.

[26] Léger P, Seydou S. Seasonal thermal displacements of gravity dams located in northern regions. ASCE J Perform Construct Facilities 2009;23(3):166-74.

[27] Azmi M, Paultre P. Three-dimensional analysis of concrete dams including contraction joint non-linearity. Eng Struct 2002;24:757-71.

[28] Hoek E, Bray J. Rock slope engineering. London, UK: Institution of Mining and Metallurgy; 1980.

[29] USACE. Engineering and design, gravity dams. Washington, DC, USA; 1995. 